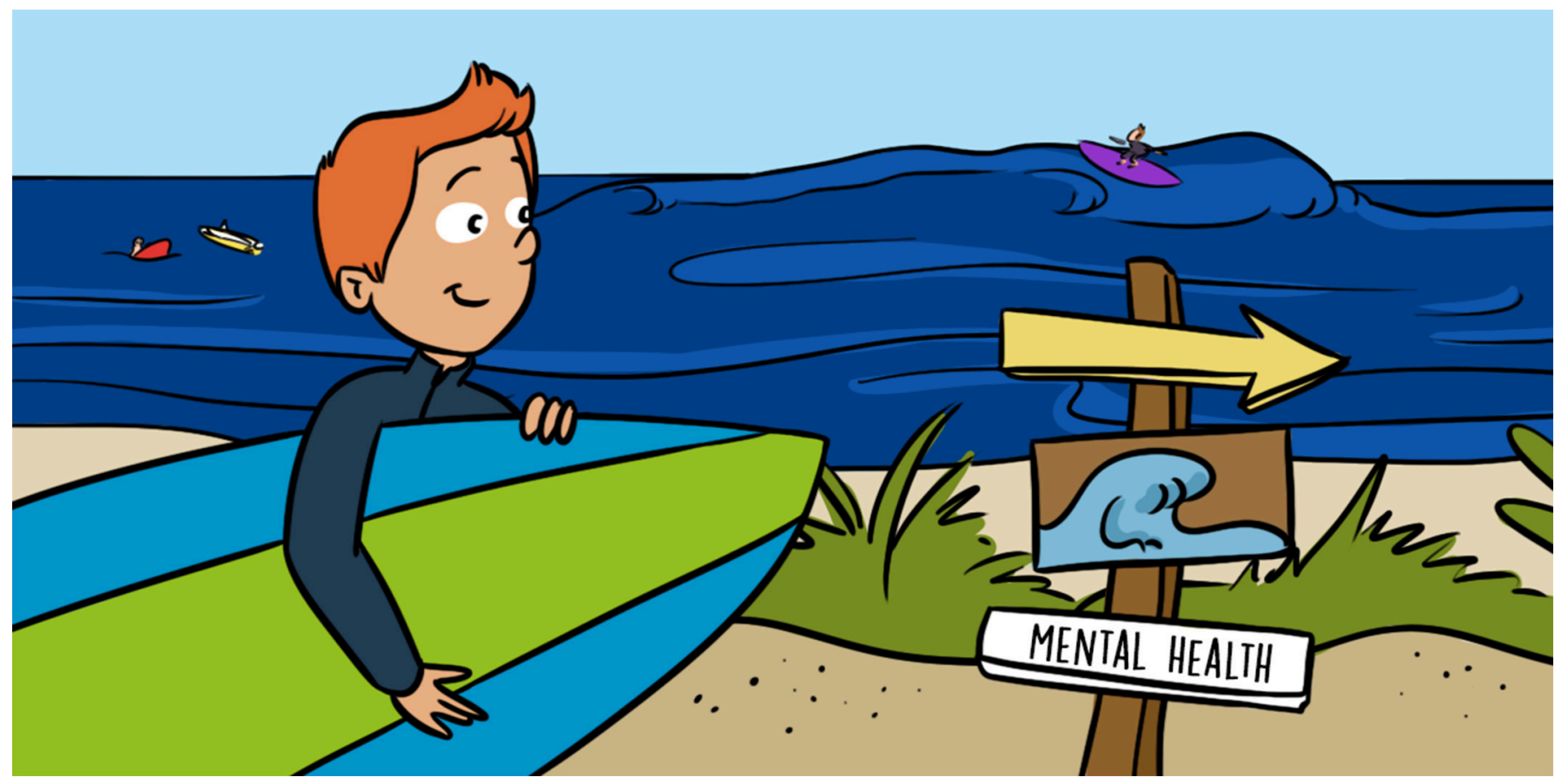

\title{
HOW SURFING COULD BE A TREATMENT FOR MENTAL |LLNESS
}

\section{Bryan D. Peck* and Jim Lagopoulos}

The Sunshine Coast Mind and Neuroscience Thompson Institute, University of the Sunshine Coast, Maroochydore, QLD, Australia

YOUNG REVIEWERS: MATTHEW FLINDERS ANGLICAN COLLEGE AGE: 14-15
When we are mentally or physically unwell we can take medication to help with the symptoms we are experiencing. When we are mentally unwell we can also talk to someone about what is going on. Sometimes medication and talking work, and sometimes not. What if we could also do an activity that improves both the mental and physical symptoms of a mental illness? What if it was an activity that you would jump out of bed to do, because it is so much fun? What if, along with being fun, the activity, also helps the areas of the brain that are linked with some mental illnesses? Surfing, as a therapy, has shown positive effects on mental health, but what impact might it have on the brain of someone with post-traumatic stress disorder (PTSD)?

\section{WHAT IS MENTAL ILLNESS?}

A mental illness is a medical condition that affects the brain, resulting in changes in a person's thoughts, feelings, and behavior. Like many 
POST-TRAUMATIC STRESS DISORDER

A mental illness that can develop in people who have been through a traumatic event that threatened their life or safety.

\section{COGNITIVE}

FUNCTION

Mental processes that allow us to carry out important daily tasks, such as memory, attention, and problem solving

\section{FIGHT-OR-FLIGHT}

A fear reaction of the brain and body in response to a threat, in which the body prepares us to either stay and fight the danger or run away.

AMYGDALA

("A-MIG-DA-LA")

A part of the brain important for emotional responses, regulation of fear and aggression, and the fight-or-flight response.

HIPPOCAMPUS ("HIPP-O-CAMP-US")

Responsible for learning and memory, as well as switching off the amygdala when there is no danger or threat.

\section{PREFRONTAL} CORTEX

An area of the brain that has a role in inhibiting the fight-or-flight response. physical illnesses, mental illness affects a person's ability to live their normal daily life. Sometimes, mental illness can make it difficult to go to work, to study, to get out of the house, or to catch up with friends and family. Some of the more common mental illnesses are anxiety disorders, clinical depression, and post-traumatic stress disorder (PTSD). Anxiety often involves problems with the fear response-this response is too elevated and occurs too often. Depression usually involves having low mood, loss of interest in activities, and low motivation for a long period of time. PTSD is another common mental illness and is the focus of this paper.

\section{WHAT IS POST-TRAUMATIC STRESS DISORDER?}

As the name suggests, post-traumatic stress disorder (PTSD) is a stress-based health condition that typically occurs after someone experiences a traumatic event. People can get PTSD after experiencing a trauma themselves (e.g., a natural disaster, accident, military combat), or by witnessing a trauma happening to someone else (e.g., seeing someone else involved in a car accident). People with PTSD experience significant changes in cognitive functioning (their thinking skills, like attention, and memory), have difficulty regulating their emotions, experience overwhelming memories and dreams relating to the traumatic event, and show an elevated fight-or-flight response, which is a response to a stressful situation in which our bodies prepare us to either stay and fight the danger or to run away. People with PTSD can also experience other negative effects as a result of living with this mental illness. For example, people with PTSD are more likely to have cardiovascular disease and diabetes. They are less likely to have healthy diets, less likely to engage in physical activity, more likely to be obese and to smoke.

\section{PTSD AND THE BRAIN}

Scientists can examine the brain in two different ways: by looking at its structure and its function. That is, scientists can measure the size and shape of different parts of the brain (structure), or they may look at the activity within and between different parts of the brain (function). Research using different brain imaging techniques has revealed that people with PTSD often have changes to both the structure and function of the brain, compared with people without PTSD. Figure 1 shows the three parts of the brain that are often looked at when we investigate PTSD: (1) the amygdala (where emotions are processed), (2) the hippocampus (where memories are stored), and (3) the prefrontal cortex (where problem-solving happens). Changes in the structure of the amygdala have been associated with the constant re-experiencing of traumatic events, which is a key symptom of PTSD. Changes in the structure of the hippocampus are associated with difficulty learning and remembering that non-threatening situations are safe. Changes in the structure of the prefrontal cortex are associated with a reduced ability to stop the fight or flight response. 
Figure 1

In PTSD, certain areas of the brain, such as the amygdala, show greater activity (up arrows) compared with healthy brains, whereas other areas, such as the prefrontal cortex and the hippocampus show reduced activity (down arrows).

\section{ADJUNCTIVE}

("AD-JUNC-T-IV")

A thing added to something else. In this case, an adjunctive therapy is a type of therapy added to traditional therapies such as medications and talk therapy.

ADVENTURE-BASED PHYSICAL ACTIVITY

Adventure-based physical activities are commonly performed in a natural setting, require high physical intensity, and include elements of risk and mental commitment.

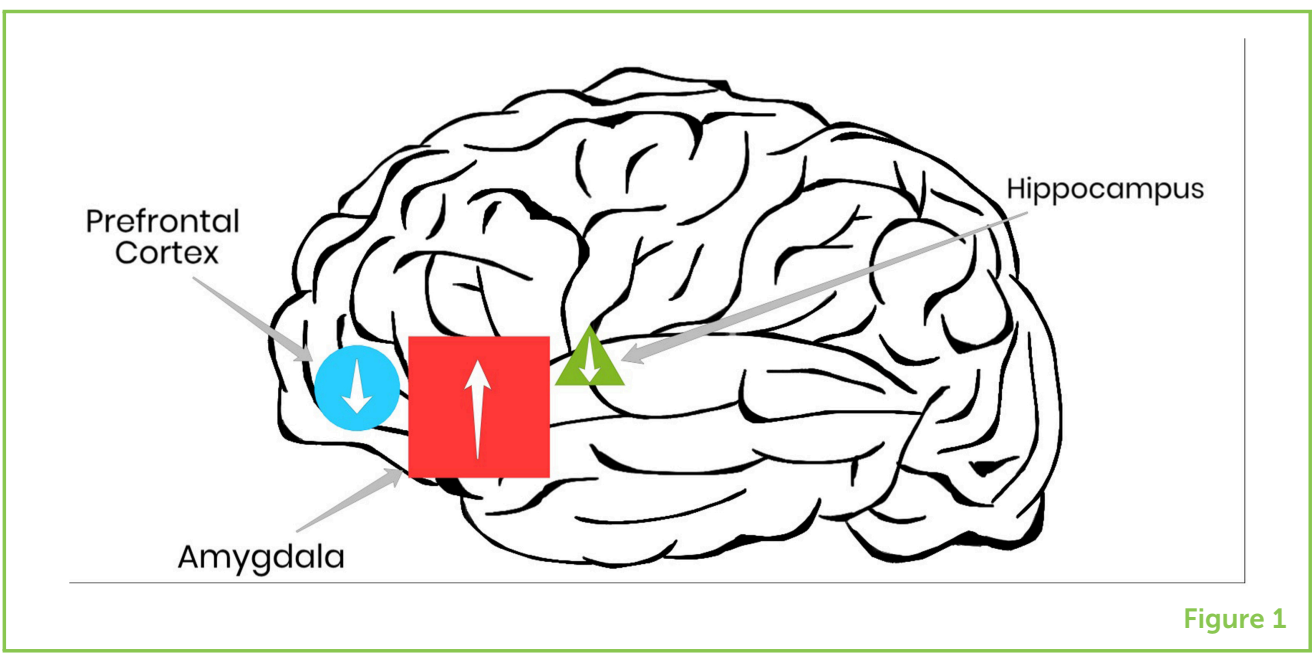

So, these three areas of the brain are often out of balance in people with PTSD.

\section{WHAT CAN WE DO FOR PATIENTS WITH PTSD?}

Current treatments for PTSD usually include medications and talk therapy. These treatments attempt to reduce symptoms, make changes in the brain, and ultimately improve quality of life. However, they do not always work, and when they do, they only work a little, or for a short time. Scientists are interested in finding and using other, better ways to treat mental illness. As such, there is increased interest in what are called adjunctive treatments, which are additional treatments that can be provided along with traditional treatments. Adjunctive treatments are particularly important for complex mental illnesses, such as PTSD.

\section{WHAT IF EXERCISE COULD HELP MENTAL ILLNESS?}

Physical activity is increasingly recognized as an important adjunctive therapy for mental illnesses. Physical activity therapies can include walking, swimming, yoga, or team and individual sports. We all know that physical activity is beneficial when it comes to preventing things like heart disease, high blood pressure, diabetes, and asthma. But you may not have known that physical activity is also linked to improvements in mental health (see Figure 2), including cognitive function (prefrontal cortex), memory (hippocampus), and stress management (amygdala). Physical activity has also been shown to reduce negative mood states, such as anger and depression, and improve positive mood states, such as feeling energized [1]. Adventure-based physical activity is an important alternative to the common sports and exercises. What are adventure-based physical activities and why are they important? They are activities that include an element of risk, they are performed in changing environments, they are of high intensity, and they require physical and mental 
Figure 2

Physical activity can help return brain functioning to healthy levels in the regions of the brain responsible for learning, problem solving, and responding to stress. For example, in the brains of people with mood disorders, physical activity can improve functioning in the prefrontal cortex and hippocampus (up arrows), and calm a hyperactive amygdala (down arrow).

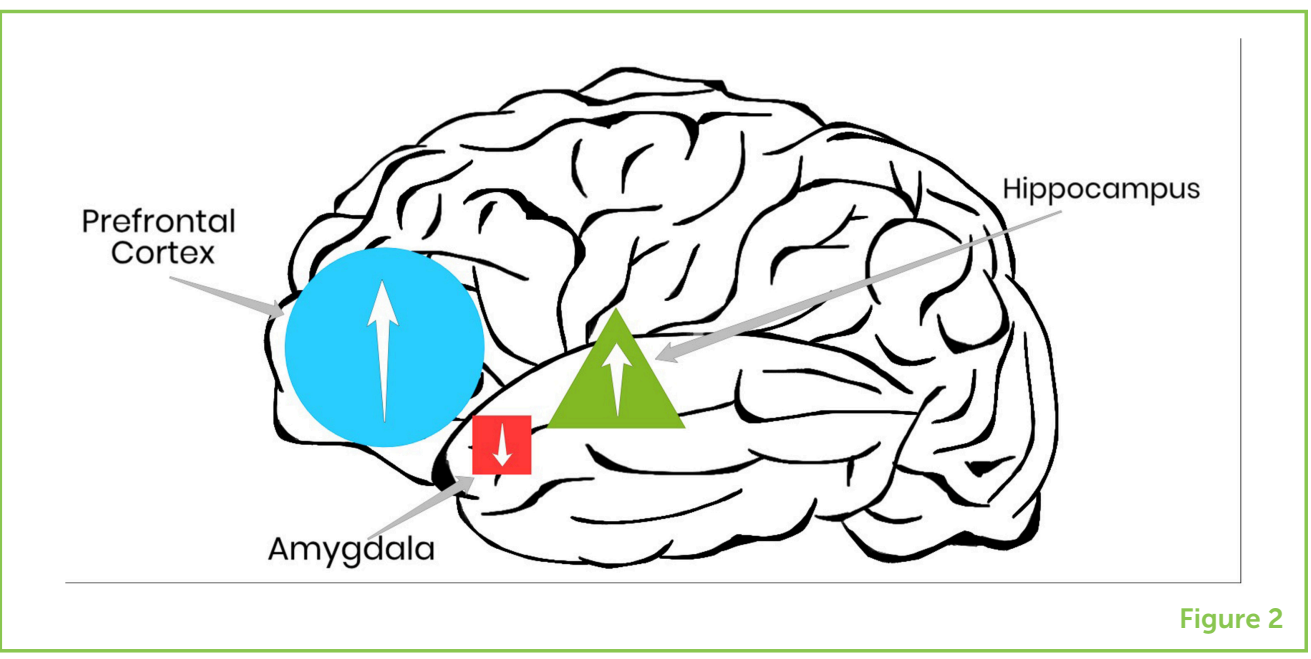

commitment. Some examples of adventure-based physical activities include rock climbing, hiking, snowboarding, and surfing. Surfing is an easily accessible activity performed by millions of people all over the world. Surfing as a therapy has been around for decades, and surfing therapy has been used on both kids with physical and mental disabilities and on combat veterans with PTSD and depression.

\section{SURFING AS A THERAPY FOR CHANGING THE BRAIN}

In order to understand the effects of surfing as an adjunctive treatment for PTSD, we will focus on three areas that highlight important elements of surfing that make it a good activity for making beneficial changes in the brain.

\section{Surfing is an Interaction with Nature}

Research shows us that exercising in natural environments can lead to positive effects on physical and mental health. In terms of mental health, scientists commonly look at the effects on a person's mood. Mood influences our feelings of satisfaction with life and our ability to deal with the ups and downs of the day, as well as the choices we make regarding our studies, work and relationships. Have you ever woken up "on the wrong side of the bed?" Mood disorders are also a major component of all mental illnesses. The brain is a complicated organ and the control of mood by the brain is no different. The prefrontal cortex, the amygdala, and the hippocampus are all involved in the regulation of mood. As it turns out, spending time in nature seems to lower stress levels, help the prefrontal cortex to focus, and lead to lower levels of mental fatigue. These effects are even greater if the physical activity is in the presence of water [2].

\section{Surfing Requires the Balance of Risk and Reward}

When we surf, we engage both mental and physical skills in a challenging environment that is constantly changing. Surfing requires 
commitment in order to manage the risk of falling off the surfboard, but is rewarded by the joy of riding the waves. In other areas of research, scientists know that those moments of feeling good involve activity in the reward pathways of the brain, including those in the prefrontal cortex. A chemical in the brain called dopamine plays a role in feeling good. In some mental illnesses, dopamine is thought to function improperly, leading to decreased desire for doing things that give us that good feeling. Can you imagine if hanging out with your friends did not feel good anymore? Surfers report the good feeling they get when catching a wave, and this feeling may help with managing their mental health, so that they have lower levels of depression and anxiety than the general population [3]. For people with PTSD, surfing could help with increasing their capacity for positive feelings like joy, and for managing mood in the face of a hyperactive fight-or-flight response.

\section{Surfing is a High Intensity Physical Activity}

Additionally, surfing is a physically demanding activity. The challenges associated with surfing are varied and include carrying the surfboard, high intensity paddling to catch a wave, push-ups to stand up on the surfboard, and balance. Research has shown that physical activity has a positive effect on multiple areas of the brain. Physical activity can change activity in the amygdala and hippocampus, which are both involved in our responses to threat and stress [4]. Physical activity can also increase the size of the hippocampus, improving its ability to let the amygdala know that there is no threat in safe situations. For example, one study showed that physical activity resulted in a $14 \%$ increase in the size of the hippocampus, after just 8 weeks of doing a cycling exercise [5].

\section{SURFING FOR PTSD}

Based on previous studies, we can predict that surfing as a therapy for PTSD will strengthen the hippocampus' ability to inhibit the fight-or-flight response and help to improve mood. Excitingly, we are looking to investigate the effects of surf therapy for people with PTSD. We are hoping to see changes in the structure and function of the three brain areas discussed in this paper. Hopefully, surf therapy will lead to improvements in the quality of life of people with PTSD.

\section{AUTHOR CONTRIBUTIONS}

BP wrote the manuscript. JL reviewed and edited.

\section{REFERENCES}

1. Basso, J. C., and Suzuki, W. A. 2017. The effects of acute exercise on mood, cognition, neurophysiology, and neurochemical pathways: a review. Brain Plast. 


\section{2:127-52. doi: 10.3233/BPL-160040}

2. Barton, J., and Pretty, J. 2010. What is the best dose of nature and green exercise for improving mental health? A multi-study analysis. Environ. Sci. Technol. 44:3947-55. doi: 10.1021/es903183r

3. Levin, B. J., and Taylor, J. 2011. Depression, anxiety, and coping in surfers. J. Clin. Sport Psychol. 5:148-65. doi: 10.1123/jcsp.5.2.148

4. Zschucke, E., Renneberg, B., Dimeo, F., Wustenberg, T., and Strohle, A. 2015. The stress-buffering effect of acute exercise: evidence for HPA axis negative feedback. Psychoneuroendocrinology 51:414-25. doi: 10.1016/j.psyneuen.2014.10.019

5. Pajonk, F.-G., Wobrock, T., Gruber, O., Scherk, H., Berner, D., Kaizl, I., et al. 2010. Hippocampal plasticity in response to exercise in schizophrenia. Arch. Gen. Psychiatry 67:133-43. doi: 10.1001/archgenpsychiatry.2009.193

SUBMITTED: 26 September 2018; ACCEPTED: 02 May 2019; PUBLISHED ONLINE: 24 May 2019.

EDITED BY: Daniel F. Hermens, University of the Sunshine Coast, Australia

CITATION: Peck BD and Lagopoulos J (2019) How Surfing Could be a Treatment for Mental Illness. Front. Young Minds 7:70. doi: 10.3389/frym.2019.00070

CONFLICT OF INTEREST STATEMENT: The authors declare that the research was conducted in the absence of any commercial or financial relationships that could be construed as a potential conflict of interest.

COPYRIGHT @ 2019 Peck and Lagopoulos. This is an open-access article distributed under the terms of the Creative Commons Attribution License (CC BY). The use, distribution or reproduction in other forums is permitted, provided the original author(s) and the copyright owner(s) are credited and that the original publication in this journal is cited, in accordance with accepted academic practice. No use, distribution or reproduction is permitted which does not comply with these terms.

\section{YOUNG REVIEWERS}

\section{MATTHEW FLINDERS ANGLICAN COLLEGE, AGE: 14-15}

Matthew Flinders Anglican College young reviewers are keen budding scientists who enjoy taking on challenges. They are a collaborative bunch of young minds, with shared interests in science, music, and sport. This group of young reviewers thoroughly enjoy being part of Frontiers for Young Minds and are excited to be involved in how science is being communicated and shaped. University of the Sunshine Coast, Australia. 


\section{AUTHORS}

\section{BRYAN D. PECK}

Bryan loves the water and being on and around the ocean. Bryan also really enjoys finding things out that help people with serious health conditions. Bryan is doing research into the effects of Adventure-based Physical Activity on the brains and lives of people who have Post-Traumatic Stress Disorder. Will there be a change in the brain? Will that change link with changes in mental illness and quality of life? We will soon see. *bryan.peck@aresearch.usc.edu.au

\section{JIM LAGOPOULOS}

Prof Jim Lagopoulos is the director of the Sunshine Coast Mind and Neuroscience-Thompson Institute. Jim has extensive experience, with more than 20 years studying the brain. Jim seeks to make sure that the results of his research benefit people with mental illness. 